\title{
A Pilot Study to Assess Feasibility of Lay Representation in Dental School Admissions Interviews
}

\begin{abstract}
Heidi Bateman, Michelle Smith, Christine Melvin, Richard D. Holmes, Ruth A. Valentine
Abstract: Regulatory bodies in the dental profession often include members of the public as a way to ensure that patient interests are represented. With student selection for admission to dental school being a multifaceted, highly competitive process, this study was motivated by curiosity about the value of involving members of the public in the admissions process. At Newcastle University School of Dental Sciences, UK, semi-structured selection interviews conducted by two members of the faculty staff are part of the process. In the 2016-17 and 2017-18 admissions cycles, lay representatives joined a number of the interview sessions. The aim of this study was to determine the feasibility of having a lay person present during the selection interview and whether this could become an integral part of the admissions process. A secondary purpose was to internally validate the processes in place for the interviews by considering the alignment of judgments of the panel and lay representatives. This study followed a two-stage, mixed-methods design. Quantitative analysis compared numerical interview scores awarded by the panel and lay representative when present. Scores for each question domain and overall interview score were compared. Qualitative analysis was carried out by conducting a focus group with lay representatives to seek insight into their experience and reflections on the interview processes. Thematic analysis was used, and overarching themes identified. The results showed no statistically significant difference between the interview panel and lay persons' scores for each domain or overall score awarded for the interview. The thematic analysis identified three overarching themes: reason for volunteering, process and training, and thoughts on style of interview used. These results suggest that involvement of lay people from the local community was feasible, and there was interest in continuing this involvement from the volunteers themselves.
\end{abstract}

Heidi Bateman, BDS, is Clinical Trainer in Restorative Dentistry and Honorary Clinical Senior Lecturer, School of Dental Sciences, Newcastle University, UK; Michelle Smith is Admissions Officer, School of Dental Sciences, Newcastle University, UK; Christine Melvin is Former Exams, Assessment, and Admissions Coordinator, School of Law, Newcastle University, UK; Richard D. Holmes, PhD, is Senior Lecturer, Hon. Consultant in Dental Public Health, and Senior Admissions Tutor, School of Dental Sciences, Newcastle University, UK; and Ruth A. Valentine, PhD, is Reader and Deputy Dean of Undergraduate Studies, School of Dental Sciences, Newcastle University, UK. Direct correspondence to Dr. Ruth Valentine, School of Dental Sciences, Newcastle University, Framlington Place, Newcastle upon Tyne, NE2 4BW, UK; Ruth.Valentine@newcastle.ac.uk.

Keywords: dental education, dental school admissions, school admission criteria

Submitted for publication 9/7/18; accepted 12/16/18; first published online 3/25/19 doi: 10.21815/JDE.019.077

$\mathrm{T}$ The route of admission to predoctoral medical and dental school programs is both a highstakes and competitive process. The number of applications per place to these programs each year in the United Kingdom (UK) is among the highest received by the Universities and Colleges Admissions Service (UCAS), ${ }^{1}$ with applications far exceeding the number of places available. Therefore, the process of admissions selection is vital for universities and potential students. It is also a subject of significant scrutiny in the published literature with a systematic review finding little agreement regarding the reliability of methods used to evaluate non-academic attributes. ${ }^{2}$ Ensuring a fair and transparent process is essential. ${ }^{3,4}$ For the students selected, it marks the start of a rigorous training program that culminates with entry into their chosen profession.

Various methods for admissions selection are currently used by dental schools in the UK. These include a combination of personal statements, previous and predicted grades, United Kingdom Clinical Aptitude Test (UKCAT) results, Situational Judgment Tests (SJTs), multiple mini-interviews (MMIs), and traditional-style interviews. The body that represents the dental schools of the United Kingdom and Ireland - the Dental Schools Council-states as the first principle in its guiding principles for the admission of dental students that "Selection for 
Dental School implies selection for the dental profession," and thus "there is a need to select those with appropriate attributes for training and entry into the profession" (p. 4). ${ }^{1}$

With a focus on getting it right at the admissions stage, predictor variables from various elements of the medical and dental admissions process have been assessed as potential predictors of success in student performance. These have included whether there are links with academic success in the program ${ }^{3,5-7}$ and as a possible predictor of professional behavior. ${ }^{8,9}$ However, whether predictive correlation exists or not, the process of selecting appropriate candidates for entry to dental school is an important one.

The consideration of the public and its interest in the standards demonstrated by the dental profession must also be remembered. ${ }^{10}$ From a regulatory perspective, the profile of representation outside the profession's direct membership and inclusion of the public and patients in quality assurance processes in clinical institutions are widely acknowledged. Involvement of lay representation by the UK General Medical Council (GMC) in its inspections of medical education providers is included in the Report of the Mid-Staffordshire NHS Foundation Trust Public Enquiry: "There should be lay or patient representation on visits to ensure that patient interests are maintained as the priority" (p. 101). ${ }^{11}$

Similarly, the UK dental regulator, the General Dental Council (GDC), includes lay representatives as members of the council and on its panels and inspection teams of dental education providers. ${ }^{12,13}$ The GDC, in its role as regulator of dental training providers in the UK, has produced Standards of Education that set out the expectations of quality assurance processes. This document contains a recommendation for the involvement of patients and/ or customers: "Patient and/or customer feedback must be collected and used to inform programme development" (p. 5). ${ }^{14}$

There are key similarities among the UK dental regulator (GDC); the Commission on Dental Accreditation (CODA), the U.S. agency that accredits all types of dental education programs; ${ }^{15}$ and the Australian Dental Council (ADC) and Dental Council of New Zealand (DC [NZ]), which are responsible for advising the ADC Board of Directors and DC (NZ) of matters relating to the joint accreditation standards. ${ }^{16}$ All these bodies have representation from the general public, with CODA having four lay members and the ADC and DC (NZ) having representation from the dental profession, academia, and the community, including the public sector and dental students.

Consideration of the oral health needs of the community has been advocated as a recommendation in the design of learning and teaching. ${ }^{17}$ Utilizing patients as teachers in the training of medical and dental students is now established in many schools, with a lesser involvement in assessment and curriculum design. ${ }^{18}$ Patient and simulated patient roles in providing feedback, enhancement of communication skills, and assessment have been explored. Newcastle University School of Dental Sciences in the UK currently includes patient feedback in various forms in the student clinical program including post clinical procedure reflection and in feedback and assessment. ${ }^{19}$ Earlier involvement in the selection of students admitted to programs to train the dental professionals of tomorrow could additionally be considered. The aim of this study was to determine the feasibility of having a lay person present during the selection interview and whether this could become an integral part of the admissions process. A secondary purpose was to internally validate the processes in place for the interviews by considering the alignment of judgments of the panel and lay representatives.

\section{Newcastle Admissions Process}

The current admissions process for student selection into either the five-year Bachelor of Dental Surgery (BDS) program or the three-year Bachelor of Science (BSc) in Oral and Dental Health Sciences program at Newcastle University has a two-phase approach. Application numbers for the BDS program are at an approximate ratio of ten applications per place and for BSc Oral and Dental Health Sciences 20 applications per place. The first phase is informed by consideration of a combination of subjects and qualifications currently/previously undertaken by candidates, UKCAT scores (for BDS only), predicted grades for current program of study, personal statements, and references.

The second phase is a semi-structured interview process, with applicants being interviewed for approximately 20 minutes by two members of dental school faculty staff (at least one being clinical). Members of the interview panel ask questions relating to a set of agreed-upon domains; personal qualities/ 
resilience; preparation and motivation for dental school; interpersonal and communication skills; teamworking; empathy; and effective learning skills. In their preparation for each interview, the selectors are provided with copies of the candidate's personal statement in advance of the panel.

Based on the interview, each evaluator gives the candidate a score on each of the domains. These domains have a framework for guidance that includes behavioral examples and contraindicators. An example in the teamworking domain would be a student's ability to show how he or she has contributed positively to a team/community/organization, whereas a contraindicator in the preparation and motivation for dental school domain may be a lack of awareness of common dental issues or the inability to discuss or articulate a balanced view. Each member of the staff scores the candidate independently, and in addition to numerical scoring, the interviewers are requested to make qualitative comments on candidates' interview performance. The resultant scores and comments are handed to the admissions team, where they are recorded in a spreadsheet (Excel) and the average question score and $\mathrm{Z}$ scores are calculated.

Management of the interview data is handled by the admissions team, which consists of two members of faculty staff (admissions tutor and deputy), who have ultimate responsibility for recruitment and selection, and two members of administrative support staff involved in recruitment and selection (admissions officer and admissions coordinator). Once students have been informed of their result, the feedback on interview performance in individual domains, interviewer comments, and numerical cutoff score for selection are available on request to them. The school's philosophy of the purpose of the interview is twofold: to show applicants what the dental school has to offer them as students, and to gain further insight about the applicants and their motivations for applying to study dentistry.

\section{Methods}

This study received a favorable opinion from the Newcastle University ethics committee (Ref: 14812/2016). The setting for this study was the School of Dental Sciences at Newcastle University in the north of England. The study followed a two-stage, mixed-methods design using quantitative interview score data and qualitative focus group data.
To aid in the recruitment of lay people, the research team approached Voice, which operates with the aim of capturing the public's vast experience, ideas, opinions, and expectations about research, innovation, and policy developments that may affect their lives. ${ }^{20}$ Membership of Voice is over 1,500 with mainly older people signed up. The position of voluntary lay interviewer was advertised though Voice online, its dedicated website, and its social media outlets (Facebook/Twitter).

Lay people interested in volunteering were asked to send a cover letter explaining why they would like to be considered, and all applicants $(n=10)$ were subsequently invited to an informal meeting with the admissions team to discuss the proposed work, training needs, and level of commitment. The only exclusion criterion was previous work in a dental profession. Five people attended the informal meetings, and four agreed to attend training.

Training in the selection process conducted with the four lay people consisted of a session to meet the admissions team in the School of Dental Sciences, a session on how the interviews are carried out and their role in it, and a session covering the university's policy on equality and diversity. The lay people were also provided with documentation relating to student Open Days, a copy of the interview form, and details of the framework used to score candidates on the interview performance. The lay people were invited to sit in on as many interviews as they could attend. Although they did not ask questions during the interview, we encouraged them to fill out the interview form and evaluation framework.

Thirty staff members of the school are involved in the admissions interviewing process; these individuals are from both scientific non-clinical and clinical backgrounds. All staff members who interview students receive an orientation (including equality and diversity training), and they shadow experienced evaluators before becoming part of an interview team. Involving lay people in a number of interviews was considered extremely valuable by the admissions panel (which consists of all staff members involved in the interview process, faculty members, and the admissions officer and coordinator). This panel meets twice annually, and its actions feed into the school's governance structures. As a number of staff members are involved in various pairings for almost all interviews, the panel felt that involving a lay person would be a good validation tool between and across interviews. 
A selection of interviews for 2016 and 2017 entry to the BDS and BSc ODHS programs had a lay person present during the interview. Interviews were conducted in the school in January and February 2016 and 2017, following our standard procedures. Applicants were made aware of the presence of lay people prior to the start of the interview and were informed why they were present. They were also informed that the lay person would not ask questions and was simply observing the process. All numerical scores and qualitative comments on interview performance were recorded on paper. Typically, interviews took place in two parallel afternoon sessions that were three hours in length. This allowed for approximately 16 candidates to be interviewed in each afternoon session. Lay individuals observed the interview and independently scored each student on the question domains, personal qualities/resilience, preparation and motivation for dental school, interpersonal and communication skills, teamworking, empathy, and effective learning skills. Interview data were nonparametric in nature. Scores on each question domain and overall interview score were compared for the lay person and the school interviewer using a repeated (paired) Friedman ANOVA.

A member of the admissions team (coauthor MS) facilitated a focus group with the lay people after the 2016 interview cycle. The aim was to collect fine-grained qualitative data that would provide insights into their experiences in the admissions process. We perceived that a focus group discussion would allow the lay people to collectively reflect on their shared experiences and would therefore generate richer data than would one-on-one interviews. Initial questions were open-ended (e.g., What was the interview process like for you? How did you prepare before coming to the interviews?), and probing questions were used to follow-up on any salient issues identified by participants. The focus group was audio-recorded with written consent from each lay person; the recording was transcribed verbatim for analysis and anonymized.

Thematic analysis was used, as explained by Braun and Clarke. ${ }^{21}$ The analytical procedure that followed was inductive (i.e., data-driven) and consisted of two steps. First, one author (RAV) read the transcripts for content to identify what Braun and Clarke called "patterns of meaning and issues of potential interest" (p. 86) and generated preliminary subthemes. In the second step, coauthors RAV and HB reviewed these subthemes and identified overarching themes.

\section{Results}

Five lay people were recruited through Voice North (three men and two women). Four of them (two men and two women) were able to attend the training session and were included in the interview process. In total, over the two selection periods (2016 and 2017), 458 interviews took place, with a lay person being present at 110 of those interviews, accounting for $24 \%$ of all undergraduate interviews held over this time. Each lay person committed to two afternoon sessions per recruitment cycle.

Quantitative analysis following a Friedman test of repeated measures ANOVA found no significant difference between the school interviewers' scores and the lay persons' scores for each domain and the overall interview score (Figure 1). Qualitative analysis of the focus group transcript identified ten subthemes with three overarching themes (Table 1). Participants identified the opportunity to use their experience gained, sometimes through the roles they had in their previous career, as reasons for volunteering. Previous occupations were teaching, law, management, and social work.

The training process went well, with feedback from the lay people being very positive (Table 1). All participants went on to offer their services for subsequent years. The lay people had the opportunity to reflect on how they would like to change the process. There were expressions of interest in asking questions of the applicants or even interacting with them outside the interview setting. However, others liked the fact that they could listen and take in the information without having to ask questions. The issue of standardization came through in the focus groups, with comments both supporting a more fluid interview process and advocating greater uniformity.

\section{Discussion}

This study found no significant differences in the scoring of any domain between the lay people and interviewing staff. This finding demonstrated consistency among individual judgments regarding the applicants' abilities to demonstrate attributes identified as important for entry to the educational programs. These data provided reassurance to the admissions team and the admissions panel that the faculty evaluations were consistent with community preferences as expressed by a small self-selected group of volunteers. High interview scores given 


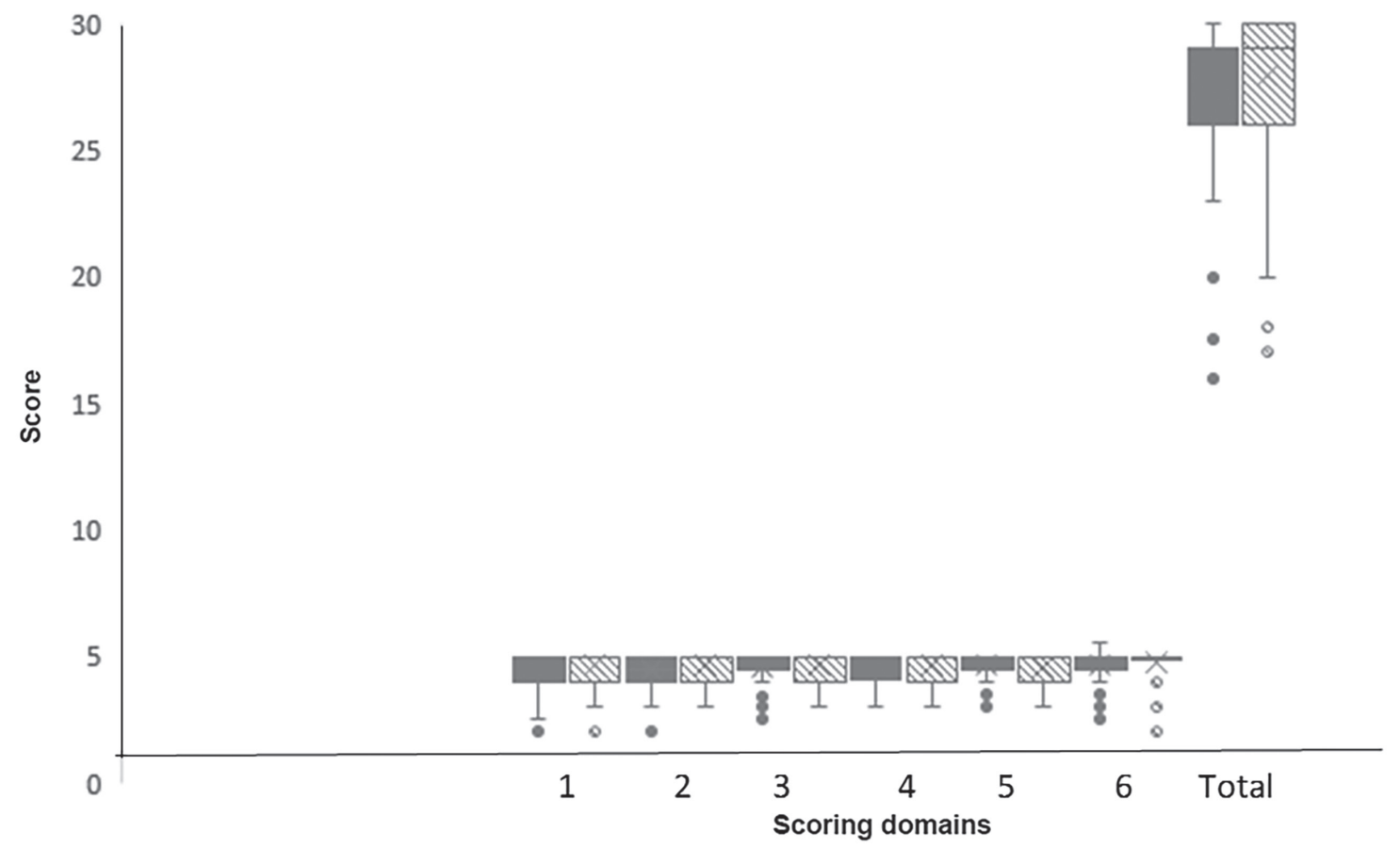

Key:

Domain 1: Preparation/motivation

Domain 2: Effective Learning Skills

Domain 2: Team-working

Domain 3: Personal Qualities

Domain 4: Interpersonal/Communication

Domain 5: Empathy/Sensitivity/Integrity

Total score

Figure 1. Comparison of interviewers' and lay persons' overall scores on each question domain and overall score

Note: The analysis was conducted with the Friedman test of repeated measure ANOVA.

by the faculty interviewers were mirrored in the lay persons' scores, and the same for low scores (Figure 1), suggesting a fair and consistent application of scoring for candidates.

The comments made in the focus group about the style of interview used were consistent with a long history of debate regarding the use of interviews, whether structured or semi-structured, with questions raised as to their fairness and effectiveness. Morris's review of the value and role of admissions interviews concluded in 1999 that there was equivocal evidence as to the reliability, validity, fairness, and use of interviews. ${ }^{22}$ The significant differences in approach to the way interviews are conducted mean comparability across studies is limited. Patterson et al.'s systematic review of the effectiveness of selection methods found that demonstration of reliability and validity was lacking in the evidence from traditional interviews. ${ }^{2}$ Uniformity of procedures and questions, while satisfying some of the arguments of poor consistency, does in itself present other challenges. The preparedness of students can arguably be a reflection of the training given by some schools in addition to books and courses designed to prepare applicants for medical and dental school interviews. The credibility of factors in which there are opportunities for preparation and training (for example, personal statements and recommendation letters) has been questioned. ${ }^{23,24}$

An important limitation of this study was the small number of lay persons involved and their relative homogeneity as a group. The ability to attend a number of full afternoon weekday sessions may have limited some who may otherwise have wished to participate. The lay volunteers were generally retired and were older people (ages of 52 years, 56 years, and 76 years at the beginning of the study; 


\section{Table 1. Results from focus group with four lay people: thematic analysis with examples of comments}

\begin{tabular}{|c|c|c|c|}
\hline Theme & Subtheme & Description & Examples of Comments \\
\hline \multirow[t]{3}{*}{$\begin{array}{l}\text { Reasons for } \\
\text { volunteering }\end{array}$} & Dental phobia & $\begin{array}{l}\text { Some people scared } \\
\text { of dentists, so } \\
\text { important to select } \\
\text { right candidate }\end{array}$ & $\begin{array}{l}\text { "Public have a phobia about dentists; therefore, it is important to } \\
\text { select the right candidate who besides knowledge has an interest in } \\
\text { helping others and can create a trusting relationship." }\end{array}$ \\
\hline & $\begin{array}{l}\text { Past dental } \\
\text { experience: } \\
\text { good/bad }\end{array}$ & $\begin{array}{l}\text { Appreciated own } \\
\text { treatment over years }\end{array}$ & $\begin{array}{l}\text { "Past experiences good and bad initially interested me in applying. } \\
\text { The most important issues to me were, apart from treatment, the } \\
\text { way the dentist communicated his/her intentions as well as general } \\
\text { conversation and communication." }\end{array}$ \\
\hline & $\begin{array}{l}\text { Personal interest/ } \\
\text { health }\end{array}$ & $\begin{array}{l}\text { Use my thinking } \\
\text { skills, work-based } \\
\text { skills, experience in } \\
\text { higher education }\end{array}$ & $\begin{array}{l}\text { "I have been a patient, trained as a patient leader by the NHS for } \\
\text { purpose of bridging the gap between health care professionals and } \\
\text { service uses." } \\
\text { "Past experience in legal practice and higher education." } \\
\text { "Putting good use of my experience of appointing staff in schools." } \\
\text { "I wanted to use my own thinking skills and keep my brain active." }\end{array}$ \\
\hline \multirow[t]{4}{*}{$\begin{array}{l}\text { Process and } \\
\text { training }\end{array}$} & Training/briefing & Thorough training & $\begin{array}{l}\text { "The briefing was excellent." } \\
\text { "A clearer understanding of the direction of questioning, especially as } \\
\text { we worked with several staff [would help]." }\end{array}$ \\
\hline & Staff & $\begin{array}{l}\text { Staff were friendly } \\
\text { and welcoming }\end{array}$ & $\begin{array}{l}\text { "Staff were all very friendly and welcoming without the importance of } \\
\text { the task being compromised." } \\
\text { "Impressed with the high quality and professionalism of all staff with } \\
\text { whom I came into contact. Everyone treated me as a colleague." }\end{array}$ \\
\hline & Environment & Positive environment & $\begin{array}{l}\text { "Very impressed with staff and students alike. Such a positive } \\
\text { environment, and it's clear that everyone is working to the same end. } \\
\text { Students are well supported during the interview process." }\end{array}$ \\
\hline & Logistics & $\begin{array}{l}\text { Time-consuming and } \\
\text { demanding on staff }\end{array}$ & $\begin{array}{l}\text { "Briefing notes were most helpful as was the organization of what is a } \\
\text { time-consuming and complex process." } \\
\text { "University admission process is very demanding, time-consuming, } \\
\text { and stressful particularly for the admissions tutor." }\end{array}$ \\
\hline \multirow[t]{3}{*}{$\begin{array}{l}\text { Thoughts } \\
\text { on style of } \\
\text { interview } \\
\text { used }\end{array}$} & $\begin{array}{l}\text { Traditional } \\
\text { interview }\end{array}$ & $\begin{array}{l}\text { Organic way the } \\
\text { interview developed } \\
\text { Traditional style } \\
\text { worked well }\end{array}$ & $\begin{array}{l}\text { "Staff responded to each person and did not follow a mechanistic } \\
\text { prescribed script. This brought out the best in the candidates and } \\
\text { allowed them to flourish." } \\
\text { "I would keep the same style and approach being used." }\end{array}$ \\
\hline & Questions asked & $\begin{array}{l}\text { Clearer set of } \\
\text { questions }\end{array}$ & $\begin{array}{l}\text { "Suggest more uniform/consistent questioning." } \\
\text { "Perhaps if the students were asked basic questions [set format], so the } \\
\text { process [is] the same with all students." }\end{array}$ \\
\hline & $\begin{array}{l}\text { Additional time } \\
\text { with students } \\
\text { outside interview }\end{array}$ & $\begin{array}{l}\text { Dialogue with } \\
\text { students and } \\
\text { communication }\end{array}$ & $\begin{array}{l}\text { "Not asking questions gives me the luxury of listening closely to each } \\
\text { candidate." } \\
\text { "Time permitting, I would ask one or two questions based on the } \\
\text { answers given by candidates." } \\
\text { "Watching how students interact would be good." }\end{array}$ \\
\hline
\end{tabular}

one did not disclose age). However, using only this small number of people allowed us to consider data from 110 individual interviews. This process permitted internal validation of the processes we have in place for interviews by considering the alignment of judgments between the interview panel and lay people and allowed the school to feel confident in the transparency of the interview process. We would recommend, however, any future studies to include a larger number of lay representatives, allowing for greater gender, age, and ethnicity mix. Including greater representation of the population would en- hance the validity of the results. Also, since the study took place at only one academic dental institution, its results may not be generalizable to other programs.

As Rosenfeld et al. pointed out, all forms of interview have a significant investment cost. ${ }^{25}$ Involving lay people in the interview process presented some logistical challenges and had human resource and financial implications for the school. We believed the benefits outweighed the costs, but in future studies these factors should be considered, especially if larger numbers of lay volunteers are included on a regular basis. 
After two rounds of the admissions process with lay people involvement, we are facing the point at which it is necessary to recruit additional lay members to our small team. We hope that our current members will help us promote this role and that we will be able to attract a diversity of backgrounds and experiences in our lay members. In the school, holding the interviews in full-afternoon sessions will continue to potentially limit the participation of some people who are unable to commit the time required. We also currently have not defined a minimum number of sessions to which lay members need to commit, but this could be considered together with targets for the proportion of interviews at which a lay member will be present.

An added benefit of this type of study was the school's involvement with the local community, allowing some of its members the opportunity to see the processes involved in selecting students who may serve their dental needs in the future. Part of the reason for the focus group was to determine if the lay volunteers would wish to participate in the future and therefore whether the process could be adopted in subsequent years with a standard proportion of more than $10 \%$ of interview panels including a lay member. Due to its relatively small-scale introduction, at the current time, the school has no plans to introduce lay person scoring into each candidate's overall performance.

\section{Conclusion}

The results of this study showed that involvement of the lay people from our local community was feasible when involving very small numbers of volunteers; however, logistical arrangements and costs need to be factored in to expand the project. There was interest in continuing from the volunteers themselves, and the approach as a whole supported the open ethos of the school and wider university. This process provided the admissions team at Newcastle University School of Dental Sciences with validation regarding our current approach to interviewing potential students for our undergraduate degree programs. The candidates rated favorably by our staff were also those highly regarded by members of our local community.

\section{Acknowledgments}

The authors would like to thank the lay volunteers involved in the admissions process.

\section{Disclosure}

The authors reported no conflicts of interest.

\section{REFERENCES}

1. Universities and Colleges Admissions Service. Medicine and allied subjects. At: www.ucas.com/ucas/subject-guide-list/ medicine-and-allied-subjects. Accessed 3 Jan. 2018.

2. Patterson F, Knight A, Dowell J, et al. How effective are selection methods in medical education? A systematic review. Med Educ 2016;50:36-60.

3. McAndrew R, Ellis J, Valentine RA. Does a selection interview predict year 1 performance in dental school? Eur J Dent Educ 2017;21:108-12.

4. Dental Schools Council. Guiding principles for the admission of dental students. 2012. At: www.dentalschoolscouncil. ac.uk/wp-content/uploads/2015/08/DSCAdmissions PrinciplesFeb2012.pdf. Accessed 6 Nov. 2018.

5. Mercer A, Abbott PV, Puddey IB. Relationship of selection criteria to subsequent academic performance in an Australian undergraduate dental school. Eur J Dent Educ 2013;17:39-45.

6. Rich AM, Ayers KMS, Thomson WM, et al. Does performance in selection processes predict performance as a dental student? Eur J Dent Educ 2012;16:27-34.

7. Ballard RW, Hagan JL, Cheramie T. Relationship between hand-skill exercises and other admissions criteria and students' performance in dental school. J Dent Educ 2015;79(5):557-62.

8. Stern DT, Frohna AZ, Gruppen LD. The prediction of professional behaviour. Med Educ 2005;39:75-82.

9. Adam J, Bore M, Childs R, et al. Predictors of professional behaviour and academic outcomes in a UK medical school: a longitudinal cohort study. Med Teach 2015;37:868-80.

10. Wilson NHF, Jones ML, Pine C, et al. Looking forward: educating tomorrow's dental team. Eur J Dent Educ 2008; $12: 176-99$.

11. Francis R. Report of the Mid-Staffordshire NHS Foundation Trust public enquiry: executive summary. London: The Stationery Office, 2013.

12. General Dental Council. Quality assurance process BDS: a guide for providers of education and training programmes of dental students. 2015. At: www.gdc-uk. org/professionals/education. Accessed 6 Nov. 2018.

13. General Dental Council. Quality assurance process, dental care professionals: a guide for providers of education and training programmes for DCPs. 2015. At: www.gdc-uk. org/professionals/education. Accessed 6 Nov. 2018.

14. General Dental Council. Standards for education: standards and requirements for providers. 2015. At: gdc-uk.org/ professionals/education. Accessed 6 Nov. 2018.

15. Commission on Dental Accreditation. At: www.ada.org/ en/coda/accreditation/coda-membership. Accessed 6 Nov. 2018.

16. Australian Dental Council. At: www.adc.org.au/About-Us/ Committees. Accessed 25 Oct. 2018.

17. Manogue M, McLoughlin J, Christersson C, et al. Curriculum structure, content, learning, and assessment in European undergraduate dental education: update 2010. Eur J Dent Educ 2011;15:133-41. 
18. Jha V, Quinton ND, Bekker HL, Roberts TE. Strategies and interventions for the involvement of real patients in medical education: a systematic review. Med Educ 2009;43:10-20.

19. Gharib I, Rolland SL, Bateman H, Ellis JS. Just one thing: a novel patient feedback model. Br Dent J 2017;222:797-802.

20. Voice. At: www.voice-global.org/. Accessed 28 Feb. 2018.

21. Braun V, Clarke V. Using thematic analysis in psychology. Qual Res Psychol 2006;3:77-101.

22. Morris JG. The value and role of the interview in the student admissions process: a review. Med Teach 1999; $21: 473-81$
23. Prideaux D, Roberts C, Eva K, et al. Assessment for selection for the health care professions and specialty training: consensus statement and recommendations from the Ottawa 2010 conference. Med Teach 2011;33:215-23.

24. Hanson MD, Dore KL, Reiter HI, Eva KW. Medical school admissions: revisiting the veracity and independence of completion of an autobiographical screening tool. Acad Med 2007;82:S8-11.

25. Rosenfeld JM, Reiter HI, Trinh K, Eva KW. A cost-efficiency comparison between the multiple mini-interview and traditional admissions interviews. Adv Health Sci Educ 2008;13:43-58. 